\title{
AUTOMATIC SYNCHRONIZATION AS THE ELEMENT OF A POWER SYSTEM'S ANTI-COLLAPSE COMPLEX
}

\author{
J. Barkāns, D. Žalostība \\ Riga Technical University, the Institute of Power Engineering, \\ 1 Kronvalda Blvd., Riga LV-1010, LATVIA \\ e-mail:diana@eef.rtu.lv
}

\begin{abstract}
In the work, a new universal technical solution is proposed for blackout prevention in a power system, which combines the means for its optimal short-term sectioning and automatic self-restoration to normal conditions. The key element of self-restoration is automatic synchronization. The authors show that for this purpose it is possible to use automatic re-closing with a device for synchronism-check. The results of computations, with simplified formulas and a relevant mathematical model employed, indicate the area of application for this approach. The proposed solution has been created based on many-year experience in the liquidation of emergencies and on the potentialities of equipment, taking into account new features of blackout development that have come into being recently.

Key words: automatic synchronization, blackout prevention, reconnection of a power system's parts.
\end{abstract}

\section{INTRODUCTION}

The power system (PS) blackouts that have occurred in the last decades are mainly caused by dangerous overloading of network cross-sections at disconnection of heavily loaded lines. When this occurs, each of the arising processes can lead to the collapse of a power system. These processes could be as follows.

First, the lines become overloaded thermally; as a result, wire sagging is built up, followed by ground fault.

Second, over wide territories a deep voltage fall occurs (a transit voltage avalanche), followed by tripping the generators by overload protection.

Third, owing to the low voltage the load turns out to be below the level required for the thermal generating stations to operate.

Fourth, loss of stability.

The only means to prevent the initiated collapse is fast load relief in the overloaded lines. This can be achieved using the optimal preventive short-term PS sectioning proposed by the authors $[1,2]$.

In this context, the method for frequency avalanche emergency liquidation [3] is of especial importance. It is known that for the cases of separation of PS deficient regions a set of anti-emergency devices includes automatics with the following functions: fast under frequency load shedding [AUFLS] for keeping the frequency in the allowable zone; slow AUFLS load shedding with automatic retiming of the failure setting for frequency restoration up to the rated level; automatic synchronization and automatic re-closing of consumer lines by the nor- 
mal frequency indications. These devices ensure self-restoration of a power system to the normal operating condition within approximately $100 \mathrm{~s}$, thus eliminating the danger of frequency avalanche. This has been proved by positive long-term experience.

At the sectioning of a power system the separated deficient region is first overloaded and then off-loaded; while in the second part of this PS the load is lost. Such short-term separation of a deficient region can be used for blackout prevention in major power systems. In this context it is important that there be a possibility to automatically reintegrate the PS parts with the help of a simplified synchronization.

In this case synchronization is to occur at an uncertain place. Its successfulness is determined by two parameters: the frequency difference (which should be small enough) and the switching-on angle. A small value of the frequency difference is ensured by the mentioned above slow load shedding automatics with auto-retiming of the failure setting. As concerns the switching-on angle, to avoid large-scale installation of special automatic equipment, in rare emergency cases the angle settings of synchronism-check devices located on all the lines can be used. Then the maximum angle will be $\pm 40^{\circ}$, with a switching-on current not exceeding $30 \%$ of the short-circuit current and allowable transient process.

Depending on the frequency difference $\Delta f(\Delta \omega=2 \pi \Delta f)$ and its changes in time (acceleration) the synchronization of PS parts can be successful or unsuccessful, which is determined by the switching-on angle, the dynamic characteristics of generators and the topology of PS parts.

We should not restrict our analysis to consideration of a two-machine scheme. Thus, for example, if nearby the synchronization place a heavily loaded line is added, the oscillations occurring at deep voltage fall can result in stability loss there, bringing about emergency complications. Therefore to extend the analysis to more complicated cases a mathematical model will be helpful.

\section{POST-EMERGENCY AUTOMATIC SYNCHRONIZATION BY SYNCHRONISM-CHECK DEVICES}

The key element in the self-restoration of the integrity of a power system is its automatic synchronization.

The automatic self-restoration of a power system's integrity is achieved via synchronization, by creation of the conditions for automatic process during which local means should be applied. Taking into account that the synchronization proceeds at an uncertain place and that the process is not controlled, in the rare emergency cases for this goal the devices already located along the lines should be used. As such, the synchronism-check devices can serve [4].

After sectioning, the voltage vectors of PS parts are rotating with respect to each other with non-synchronous speed. Considering the motion of these vectors we can assume one of them (the voltage vector of the PS part with a power surplus) to be immovable - e.g. vector $U_{s}$, whereas the other (the voltage vector of a deficient part, $\left.U_{g}\right)$ as rotating around the former $\left(U_{s}\right)$ with a rotational speed (angular frequency) $\Delta \omega=\omega_{g}-\omega_{s}$ : 


$$
\dot{U}_{s}=U_{s}, \quad \dot{U}_{g}=U_{g} e^{j \delta}
$$

Here $\delta$ is a continuously varying angle of the voltage vector; if $0<\delta<180^{\circ}$ then $U_{g}$ leads $U_{s}$, and if $0>\delta>-180^{\circ}$ then it lags behind.

As known, the time dependence of the angle is characterized by angular velocity $\Delta \omega=d \delta / d t$; in turn, the time dependence of angular velocity is characterized by the angular acceleration $a=d \Delta \omega / d t$. The positive direction of the vector rotation is counter-clockwise. If the frequency of the separated part is greater than that of the power system, the frequency difference is positive, and voltage vector $U_{g}$ moves counter-clockwise, and in the case this frequency is lower than in PS the mentioned difference is negative and the vector's motion is clockwise.

A synchronism-check device is normally activated at the angle of $\pm \delta$, and operates after time delay $t_{d}$. Successful synchronization is necessary since during the time delay (for example, 1s) the voltage vectors have not to go out of the angle range shown in Fig. 1.
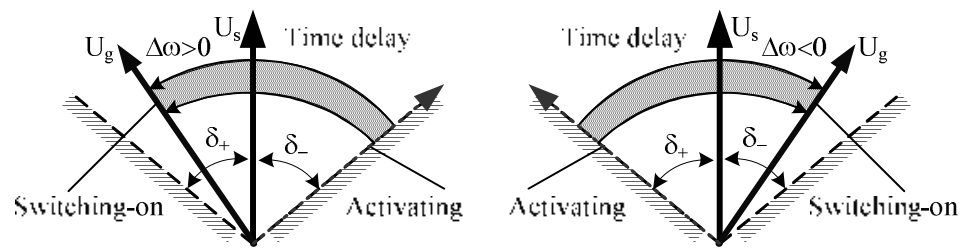

Fig. 1. The working zone of a synchronism-check relay.

We will assume that the motion of vectors is uniform: $\Delta \omega=$ const; $d \Delta \omega / d t=0$; then for synchronization to be successful it is necessary that the following condition is fulfilled:

$$
\left\{\begin{array}{lll}
\delta_{-}-\delta_{+} \leq t_{d} \cdot 360 \cdot \Delta f_{-}, & \text {if } & \Delta \omega<0 \\
\delta_{+}-\delta_{-} \geq t_{d} \cdot 360 \cdot \Delta f_{+}, & \text {if } & \Delta \omega>0
\end{array}\right.
$$

Here and further, unless otherwise specified, the time and time constants are expressed in seconds, the angles - in degrees, the angular frequency - in radians; the meaning of indices is: $r$ - for the quantity expressed in radians, ${ }^{*}-$ per unit (p.u.), +- for a positive value, -- for a negative one; for transition from radians to degrees, $\mathrm{Hz}$, and seconds the following formulas are used:

$$
\begin{aligned}
& \Delta \omega=2 \pi \Delta f ; \quad \Delta \omega_{*}=\frac{\Delta \omega}{\omega_{0}}=\Delta f_{*}=\frac{\Delta f}{f_{0}} ; \\
& t_{*}=\omega_{0} t=2 \pi f_{0} t=314 t ; \quad \delta=\left(360^{\circ} / 2 \pi\right) \delta_{y} .
\end{aligned}
$$

At a $1 \mathrm{~s}$ time delay and a $\pm 40^{\circ}$ angular range the device switches on under the condition that in the post-emergency stage the frequency difference does not exceed $0.22 \mathrm{~Hz}$ :

$$
80 \geq 360 \cdot \Delta f \quad \Rightarrow \Delta f \leq 0.22 \mathrm{~Hz} .
$$


Reduced time delay of the device would make it possible to perform synchronization at greater frequency differences. For example, if we reduce the time delay down to $0.6 \mathrm{~s}$, this would allow successful synchronization at the maximum frequency difference of $0.37 \mathrm{~Hz}$.

\section{SWITCHING-ON ANGLE}

As could be seen in Fig. 1, four switching-on modes are possible: the vectors are approaching each other; the vectors are moving apart; one of them leads the other; one of them lags behind the other [5]. Depending on the sign of the switching-on angle the separated part starts generating (at positive angles) or consuming (at negative angles) the active power. In turn, depending on the angular velocity difference there occurs acceleration or deceleration. These processes could be shown in a simplified manner using the equal area criterion in which the separated part is to be connected to the infinite power busbar (see Fig. 2).

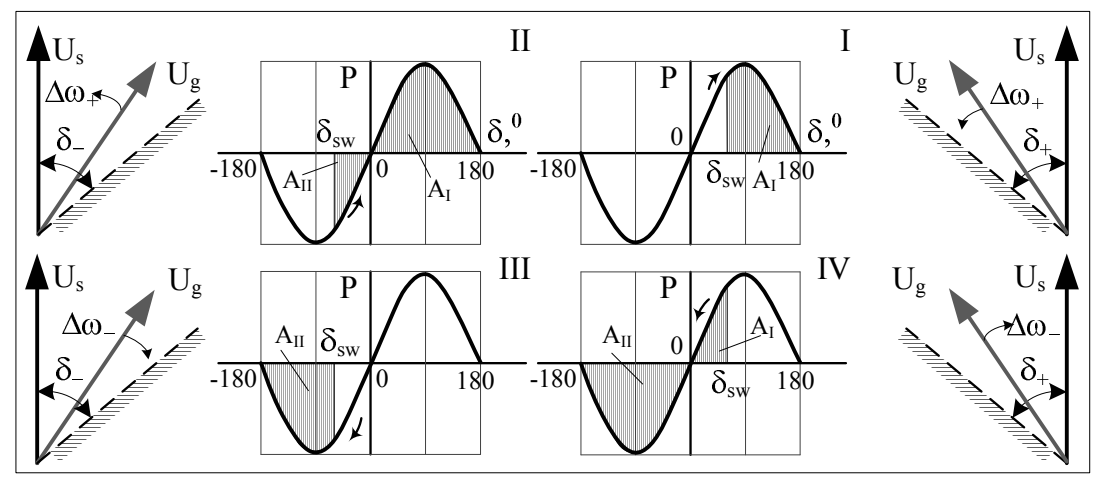

Fig. 2. The switching-on modes.

In the first case, the switching-on occurs at a positive angle (the vectors are moving apart); at the first instant the active power generation to the system and the deceleration take place. The angular velocity of the parts to be synchronized exceeds the system's velocity and it continues therefore to slow down under the system's influence until reaches the PS synchronous velocity. For successful synchronization the kinetic energy accumulated during the rotor's motion must be smaller than the energy needed for deceleration

$$
\frac{T_{j . r} \Delta \omega_{*}^{2}}{2} \leq A_{I_{*}},
$$

where

$$
A_{I_{*}}=\int_{\delta_{s w}}^{180^{\circ}} P_{m_{*}} \sin \delta_{s w} d \delta_{s w}=P_{m_{*}}\left(1+\cos \delta_{s w}\right),
$$

where $P_{m} \quad$ is the maximum power;

$\delta_{s w} \quad$ is the switching-on angle;

$T_{j . r} \quad$ is the mechanical starting time, rad;

$\Delta \omega_{*}$ is the difference of the angular velocities of PS parts, p.u.; 


$$
\begin{aligned}
& A_{I_{*}} \text { is the deceleration area energy; } \\
& A_{I I_{*}} \text { is the acceleration area energy. }
\end{aligned}
$$

In the second case the switching-on occurs at a negative angle (the vectors are approaching each other); at the first instant the active power consumption from the system and the acceleration take place. The angular velocity of the parts to be synchronized exceeds the system's velocity and it starts therefore to slow down under the system's influence until reaches the PS synchronous velocity. For successful synchronization the kinetic energy accumulated during the rotor's motion and the energy of rotor acceleration must be smaller than the energy needed for deceleration:

$$
\frac{T_{j . r} \Delta \omega_{*}^{2}}{2}+A_{I I_{*}} \leq A_{I_{*}} .
$$

In the third case the switching-on occurs at a negative angle (the vectors are moving apart); at the first instant the active power consumption from the system and the acceleration take place. The angular velocity of the parts to be synchronized is smaller than the system's velocity and it starts therefore to accelerate under the system's influence until reaches the PS synchronous velocity. For successful synchronization the kinetic energy accumulated during the rotor's motion should be smaller than the energy needed for acceleration:

$$
\frac{T_{j . r} \Delta \omega_{*}^{2}}{2} \leq A_{I I_{*}} .
$$

In the fourth case the switching-on occurs at a positive angle (the vectors are approaching each other); at the first instant the active power generation to the system and the acceleration take place. The angular velocity of the parts to be synchronized is smaller than the system's velocity and it starts therefore to accelerate under the system's influence until reaches the PS synchronous velocity. For successful synchronization the kinetic energy accumulated during the rotor's motion and the energy of rotor deceleration should be smaller than the energy needed for acceleration:

$$
\frac{T_{j} . r \Delta \omega_{*}^{2}}{2}+A_{I_{*}} \leq A_{I I_{*}} .
$$

In turn, the switching-on angles, depending on the rotational direction of the split part's voltage vector, could be found as

$$
\delta_{s w}=\left\{\begin{array}{lll}
\delta_{+}+360^{\circ} \cdot \Delta f_{-} \cdot t_{d}, & \text { if } & \Delta \omega<0 \\
\delta_{-}+360^{\circ} \cdot \Delta f_{+} \cdot t_{d}, & \text { if } & \Delta \omega>0
\end{array}\right.
$$

For example, if $\Delta f=-0.12 \mathrm{~Hz}$ (the frequency in the separated part is lower than the system's frequency) then, according to (9):

$$
\begin{aligned}
& \text { at } t_{d}=1 \mathrm{~s}, \quad \delta=40-360 \cdot 0.12 \cdot 1=-3^{\mathrm{o}} ; \\
& \text { at } t_{d}=0.6 \mathrm{~s}, \quad \delta=40-360 \cdot 0.12 \cdot 0.6=14^{\mathrm{o}} .
\end{aligned}
$$


The dependence of switching-on angle on the frequency difference $\Delta f$ at various time settings is shown in Fig. 3.

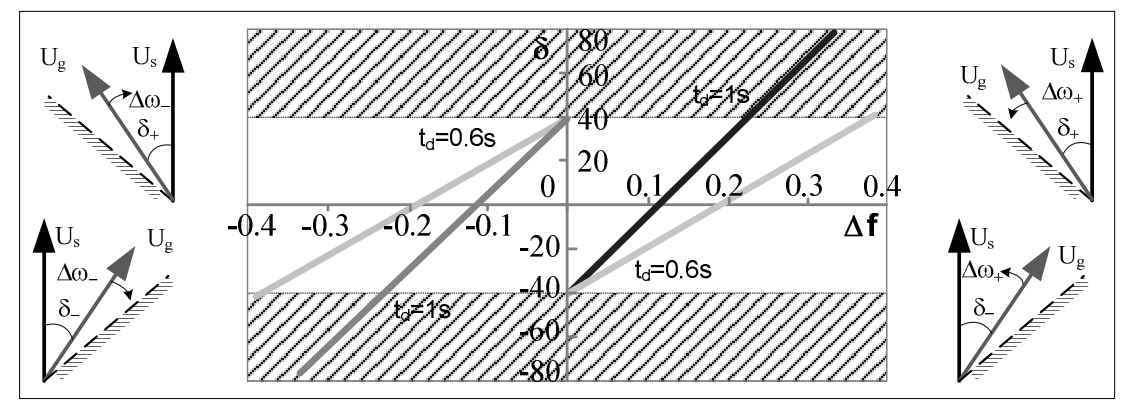

Fig. 3. Switching-on angle vs. frequency difference and time delay.

From the above consideration it follows that if synchronism-check devices with the time delay of $1 \mathrm{~s}$ are used, at the frequency difference $|\Delta f|<100 \mathrm{mHz}$ and the device being switched on, the voltage vectors are approaching each other, whereas at $|\Delta f|>100 \mathrm{mHz}$ they are moving apart.

\section{INFLUENCE OF SYSTEM ACCELERATION ON THE POST-EMERGENCY SYNCHRONIZATION PROCESS}

The system acceleration influences the synchronization process from two aspects - those of the switching-on angle and the transient process trajectory. culated as

The acceleration creates an additional change of angle $\Delta \delta$, which is cal-

$$
\Delta \delta_{r}=\int_{0}^{t} \Delta \omega \cdot t_{d} \cdot d t \Leftrightarrow \Delta \delta=\int_{0}^{t} 360^{\circ} \cdot \Delta f \cdot t_{d} \cdot d t
$$

Assuming that the processes are going with a uniform acceleration $a_{r}=$ $=d \omega / d t=$ const, the switching-on angles can be calculated as [4]

$$
\delta_{s w_{r}}=\delta_{\bar{\mp}_{r}}+\Delta \omega_{ \pm} \cdot t_{d}+a_{ \pm_{r}} \cdot t_{d}{ }^{2} / 2
$$

After transition from radians to $\mathrm{Hz}$ and degrees, the switching-on angle (assuming that the directions coincide for acceleration and for the rotation of the separated part's voltage vector) will be:

$$
\delta_{s w}=\left\{\begin{array}{lll}
\delta_{+}+360^{\circ} \cdot \Delta f_{-} \cdot t_{d}+360^{\circ} \cdot a_{-} \cdot t_{d}{ }^{2} / 2, & \text { if } & \Delta \omega<0 \\
\delta_{-}+360^{\circ} \cdot \Delta f_{+} \cdot t_{d}+360^{\circ} \cdot a_{+} \cdot t_{d}{ }^{2} / 2, & \text { if } & \Delta \omega>0
\end{array}\right.
$$

The variation of the switching-on angle at uniform acceleration, various frequency differences and delay times is shown in Fig. 4.

Figure 4 clearly demonstrates significance of the acceleration-angle dependence: from the viewpoint of synchronization the process is to go with minor acceleration so that the vector remains in the operation zone of the device during 
the time delay. If under the influence of acceleration the phase shift modulus decreases, the synchronization will be successful, and if this modulus increases it will be unsuccessful.

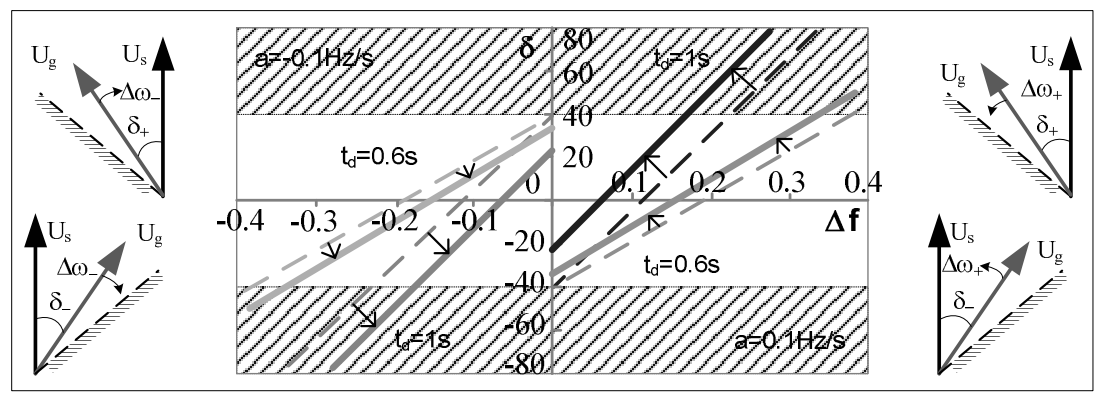

Fig. 4. The influence of acceleration on synchronization parameters.

In the case of successful synchronization, after switching-on, the angle in a transient process increases up to the maximum $\left(\delta_{\max }\right)$; after that the oscillations converge (Fig. 5).

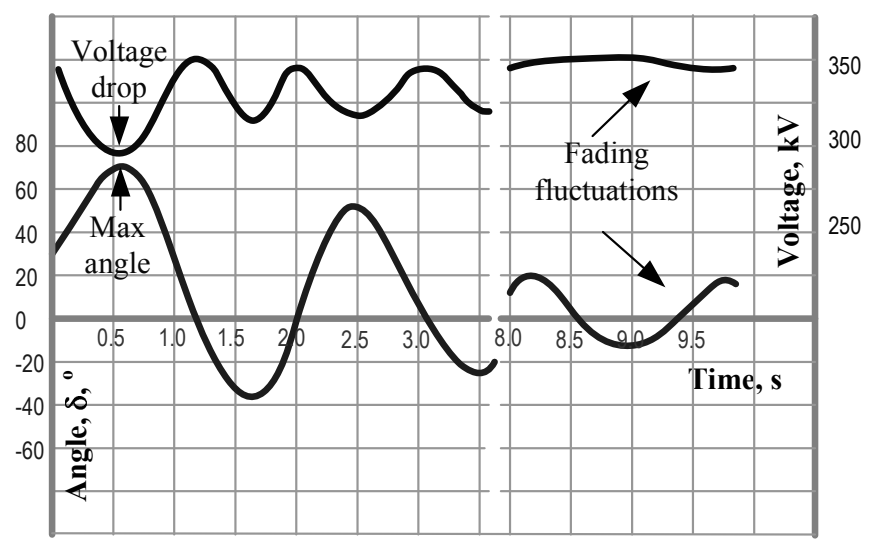

Fig. 5. Transient process of successful synchronization.

\section{THE TRAJECTORY OF SYNCHRONIZATION PROCESS}

The synchronization transient process can be described using phase plane trajectories where the relationships are established between the switching-on angles $\delta$ allowable for PS generators and the frequency differences $\Delta f$ (or slip $s$ ). Such a trajectory is determined by the specific system's and switching-on parameters: the torque of the turbine, synchronous and asynchronous torques of the generator (the damping and excitation effects), the motion accelerations of PS parts, and the switching-on angle.

The trajectories could be divided as follows [6]:

a boundary trajectory (trajectory 1 in Fig. 6) which asymptotically approaches the equilibrium-unstable or critical point, i.e. $s \rightarrow 0, \delta \rightarrow \delta_{c r}$, and separates a stable operating condition from an asynchronous one; 
limiting boundary trajectories (trajectory 2 in Fig. 6) which embrace the point of stable operating condition taking account of, e.g., the maximally allowable angle $\delta_{\max }$ or actually possible switching-on angles $\delta_{s w}$.

Synchronization will be successful if the switching-on point $(\delta ; \Delta f)$ is located in the coordinate system's area limited by the boundary trajectory that separates a stable operating condition from an unstable one, and by the actually possible switching-on angles $\delta_{\max . s w}$.
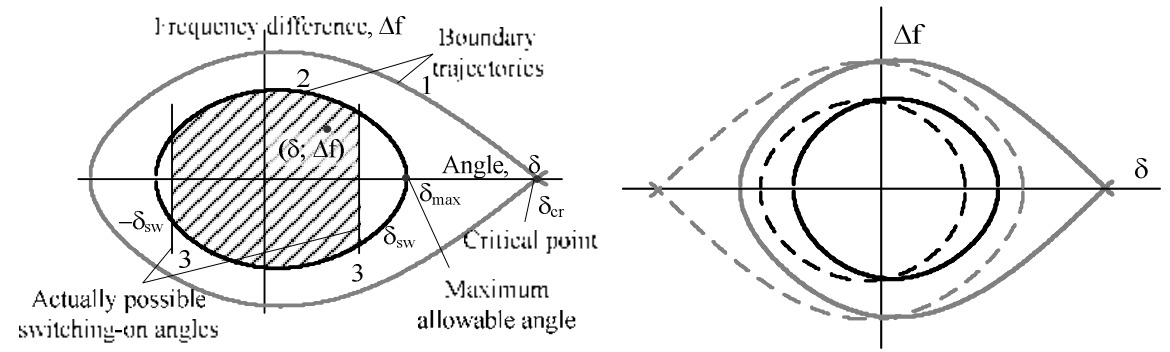

Fig. 6. The phase trajectory of a power system taking into account acceleration.

The trajectory shape is essentially changed by acceleration of the system to be synchronized that arises under the influence of power deficit or excess at the frequency recovering up to the normal level. If this acceleration is positive (favouring the convergence of voltage vectors), the boundary trajectory is extending. At the same time, if the acceleration is negative, the probability for the process to be successful decreases. This case should be taken for a basis as the worst. The trajectories $\Delta f=f(\delta)$ are symmetrical relative to the $\delta$-axis and to the $\Delta f$-axis if there is no acceleration (Fig. 6).

At the same time, the boundary trajectory can be extended by damping, which raises the probability of a successful result.

For a structurally simple system, possible pull of a PS generator into synchronism in a first approximation can be defined based on the equation of generator rotor motion:

$$
\frac{T_{j_{r}} \Delta \omega_{*}{ }^{2}}{2}=\int_{\delta}^{\delta_{\max }}\left(P_{m_{*}} \sin \delta-\frac{a}{f_{0}} T_{j}\right) d \delta,
$$

where $\Delta \omega_{*}$ is the difference between angular frequencies relative to the rated value, p.u.;

$T_{j_{r}}$ is the mechanical starting time (constant of a system's inertia), rad, $\left(T_{j}-\right.$ in $\left.\mathrm{s}\right)$;

$f_{0} \quad$ is the rated frequency, $\mathrm{Hz}$;

$P_{m_{*}}$ is the maximum transmitted power, p.u.;

$a \quad$ is the uniform acceleration of a system's part, $\mathrm{Hz} / \mathrm{s}$.

The left side of the motion equation is equal to kinetic energy $A$.

Taking into account that

$$
P_{m_{*}}=\frac{E_{*} U_{*}}{x_{\Sigma_{*}}}
$$


by transformation we obtain:

$$
\begin{gathered}
\frac{T_{j . s} \pi \Delta f^{2}}{f_{0}}=\frac{E_{*} U_{*}}{x_{\Sigma_{*}}}\left(\cos \delta-\cos \delta_{\max }\right)-\frac{a}{f_{0}} T_{j . s}\left(\delta_{\max }-\delta\right) \\
\Rightarrow \Delta f=\sqrt{\frac{E_{*} U_{*} f_{0}}{x_{\Sigma_{*}} \pi}\left(\cos \delta-\cos \delta_{\max }\right)-\frac{a}{\pi}\left(\delta_{\max }-\delta\right)},
\end{gathered}
$$

where $x_{\Sigma_{*}}$ is the reactance to the synchronization place, p.u.

\section{INFLUENCE OF VOLTAGE VARIATIONS ON THE POST-EMERGENCY SYNCHRONIZATION PROCESS}

When reconnection of PS parts proceeds at a non-optimal angle, at the beginning of a transient process the maximum angle can reach an unallowably large value from the viewpoint of voltage drop. In this case the equalizing power $S$ and reactance $\Sigma x_{i}$ cause, apart from the voltage drop owing to the load, an additional voltage drop:

$$
\Delta U \approx \frac{S}{U_{g}} \sum_{i=1}^{n} x_{i}
$$

where $U_{g}$ is the output voltage of the generating source.

Then the voltage at the transit point will be [6]:

$$
\begin{aligned}
\dot{U}_{t r} & =\frac{U_{g} e^{j \delta} x_{1}+U_{s} x_{2}}{x_{1}+x_{2}}= \\
& =\frac{U_{g} x_{1}}{x_{12}} \cos (\delta)+j \frac{U_{g} x_{1}}{x_{12}} \sin (\delta)+\frac{U_{s} x_{2}}{x_{12}},
\end{aligned}
$$

where $x_{1}$ and $x_{2}$ are the reactances from the transit point to sources $U_{s}$ and $U_{g}$;

$x_{12}=x_{1}+x_{2}$.

Employing Eq. (17), a plot could be constructed that would show the voltage changes along the transit line depending on the angle (in Fig. $6 U_{s}=U_{g}$, for the cases when $x_{1}<x_{2}$ and $x_{1}>x_{2}$ ). Connecting the beginnings of vectors $U_{s}$ and $U_{g}$ and assuming the connection point to be the origin of coordinates, with $U_{s}$ fixed, we obtain that the end of vector $U_{g}$ describes a circle with the centre at the origin of coordinates, while the end of vector $U_{g}$ describes a circle with radius $U_{g} x_{1} /\left(x_{1}+x_{2}\right)$ and the centre at the point located on vector $U_{s}$ at distance $U_{s} x_{2} /\left(x_{1}+x_{2}\right)$ from the origin.

Figure 6 clearly shows that the voltage at the transit point decreases down to zero at the angle $\delta=180^{\circ}$ if the vector moduli are equal $\left(U_{s}=U_{g}\right)$. Such being the case, the point is called the centre of oscillations. As a result, voltage decreases in a wide territory, which leads to the danger of emergency at the related generating sources [8]. Therefore we must choose the conditions for synchronization at which the voltage decrease during the transient process will be restricted. 


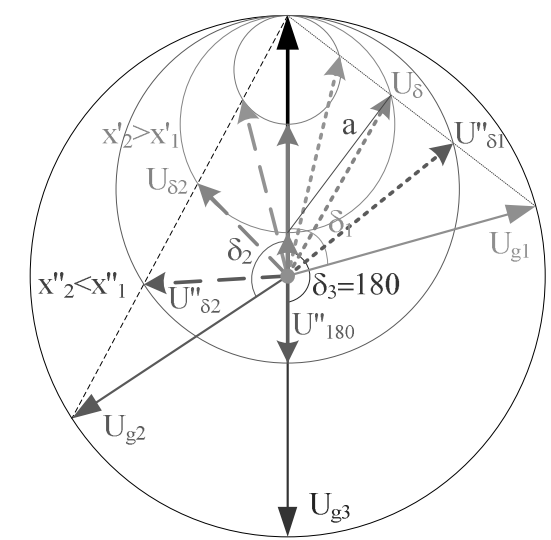

Fig. 7. Voltage variations along the transit line $\left(U_{s}=U_{g}\right)$.

The voltage changes along the transit line at different distances and different mutual angles could be found also using Fig. 7. The $U_{s}$ vector is fixed perpendicularly to the cross-cut whose length is determined by the total reactance, whereas $U_{g}$ is depicted as rotating along the circular line. The straight line that connects $U_{s}$ and $U_{g}$ vectors' ends allows finding the voltages at intermediate points. For example, in the worst case when $\delta=180\left(U_{g 3}\right)$, such a straight line allows for determination of the minimum voltages at all the intermediate points (the vectors within intermediate intervals will be perpendicular to the $x$-axis, with their ends located on this straight line); in turn, at the point of its intersection with the $x$-axis the oscillation centre is located.

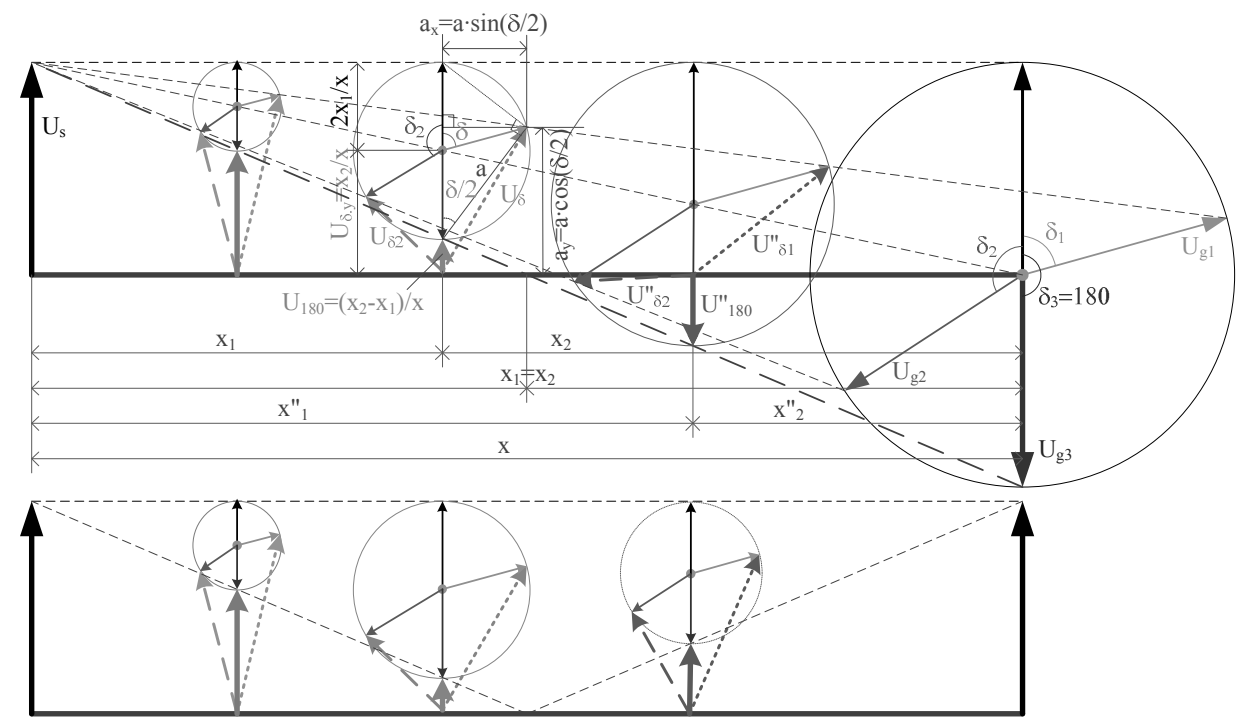

Fig. 8. Voltage variations at transit points.

In Fig. 8, the bold vectors show the voltages at transit points at different distances from the oscillation centre of voltage decrease. Since the vectors $U_{s}=U_{g}$ form the legs of an equilateral triangle, while the diameter of $U$ vector circumference is equal to $U_{s}$, the angle between $U_{s}$ and $U_{t r}$ is equal to a half of angle $\delta$ (mutual for the voltages). 
It is seen that in the case when the load centre is closer to $U_{s}\left(x_{1}<x_{2}\right)$ voltage $U_{g}$ shifts in phase from zero to $\delta_{0}^{\prime}<90$.

The values of voltage in dependence on the angle and connection place are calculable as the moduli of vector (see Eq. (17)):

$$
\begin{gathered}
\left|\dot{U}_{t r}\right|=\sqrt{\left(\frac{U_{g} x_{1}}{x_{1}+x_{2}} \cos (\delta)+\frac{U_{s} x_{2}}{x_{1}+x_{2}}\right)^{2}+\left(\frac{U_{g} x_{1}}{x_{1}+x_{2}} \sin (\delta)\right)^{2}} ; \\
U_{t r}=\sqrt{\left(\frac{U_{g} x_{1}}{x_{1}+x_{2}}\right)^{2}+\left(\frac{U_{s} x_{2}}{x_{1}+x_{2}}\right)^{2}+2 \frac{U_{g} x_{1} U_{s} x_{2}}{\left(x_{1}+x_{2}\right)^{2}} \cos (\delta) .}
\end{gathered}
$$

If the moduli are equal, the voltage variations at different transit points can be calculated in the following manner:

$$
U_{t r}=U_{s} / x_{12} \sqrt{x_{1}^{2}+x_{2}^{2}+2 x_{1} x_{2} \cos (\delta)} .
$$

The results of calculations are shown in Fig. . 9.

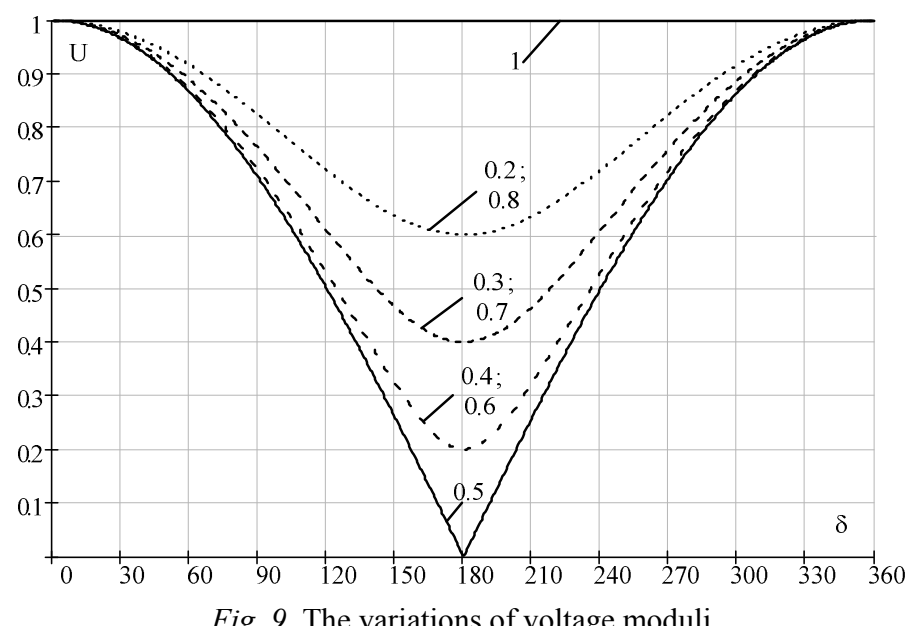

Fig. 9. The variations of voltage moduli

In the case when the TL connection point is at the oscillation centre $(0.5$ or $x_{1}=x_{2}$ ), at $180^{\circ}$ the voltage falls down to zero. The voltage at other angles for the connection that is located in the middle between the generating sources is calculated as

$$
U_{t r}=U_{s} \cos (\delta / 2) .
$$

For example, if the angle is limited to $\delta_{\max }=90^{\circ}$, the voltage at the oscillation centre will for a short time decrease down to $0.707 U_{s}$, while at $\delta_{\max }=65^{\circ}-$ down to $0.84 U_{s}$.

\section{RESTRICTION OF THE POST-EMERGENCY SYNCHRONIZATION PROCESS}

Large angles $\left(\delta \rightarrow 180^{\circ}\right)$ in the transient process can cause a danger of stability loss in the zone of PS oscillation centre if there are heavily loaded transmission 
lines. Therefore the maximum angle $\delta_{\max }$, which depends on the switching-on angle $\delta$, frequency difference $\Delta f$ and acceleration $a$, should be restricted. The maximum angle $\delta_{\max }$ can approximately be defined using Eq. (15) but in the absence of acceleration, i.e.:

$$
\delta_{\max }=\arccos \left(\cos \delta-\frac{T_{j} \pi \Delta f^{2}}{f_{0} P_{m}}\right) .
$$

At known $T_{j}$ and $P_{m}$, using (15), (18) and (21) a nomogram could be constructed to show the changes in the maximum angle and voltage at the TL connection point depending on the switching-on angles and frequency differences (see Fig. 10).

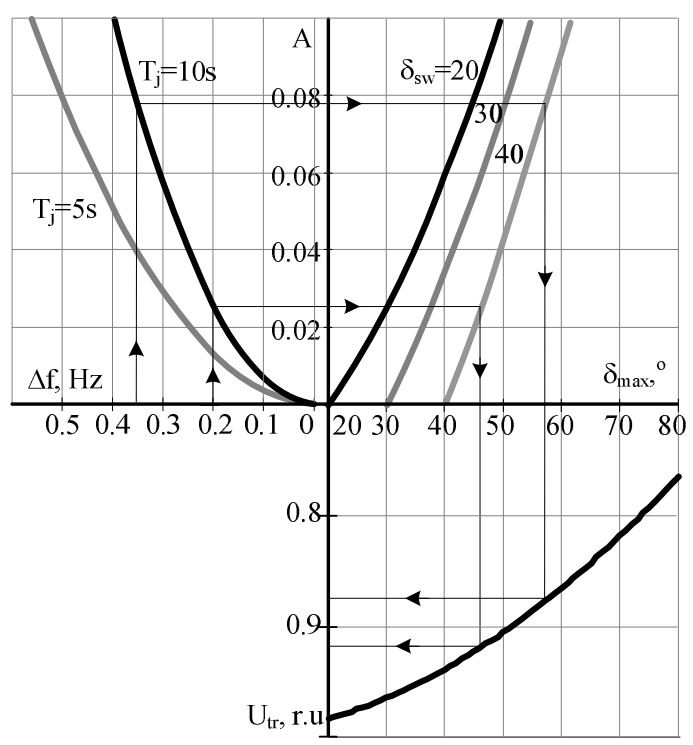

Fig.10. Calculation nomogram.

Figure 10 clearly shows that an excessive frequency difference, adding to the complexity of a transient synchronization process, can cause a voltage fall in separate parts of a power system, which makes the process unsuccessful.

For example:

$$
\begin{aligned}
& x_{\Sigma}=2.9, \quad E=1, \quad U=1, \quad T_{j . s}=10 ; \\
& \delta_{\max }=\arccos \left(\cos \delta-1.82 \Delta f^{2}\right) . \\
& \delta=40^{\circ} \quad \Delta f=0.1 \quad \Rightarrow \delta_{\max }=\arccos (0.748)=42^{\circ}, \\
& \delta=40^{\circ} \quad \Delta f=0.2 \quad \Rightarrow \delta_{\max }=\arccos (0.695)=46^{\circ}, \\
& \delta=40^{\circ} \quad \Delta f=0.4 \quad \Rightarrow \delta_{\max }=\arccos (0.469)=62^{\circ}, \\
& \delta=40^{\circ} \quad \Delta f=0.6 \quad \Rightarrow \delta_{\max }=\arccos (0.105)=84^{\circ} .
\end{aligned}
$$

The voltage values at the transit oscillation point and the corresponding frequency differences will be: $0.934,0.921,0.857$, and 0.743 . The behaviour of 
transient process is shown in Fig. 10. It is easy to verify that at $\Delta f=0.6 \mathrm{~Hz}$ in the synchronization process a deep voltage fall will be observed at the oscillation centre even at switching-on angle being $\delta_{m \cdot s w}=30^{\circ}$.

The above consideration allows for the conclusion that a fast and successful synchronization aiming at automatic self-restoration of a power system is possible with the help of synchronism-check devices.

\section{THE USE OF A MATHEMATICAL MODEL FOR COMPUTING THE SYNCHRONIZATION PROCESS}

The run of a synchronization process can be verified on the mathematical model developed by V. Ivanov in the framework of MUSTANG program (1990 2005, Copyright of Vladimir Ivanov Group) [4, 7]. For this purpose in the starting position the parts of a power system that can be modelled with the required precision (i.e. such its parameters as acceleration, damping, regulation and excitation) should operate separately. These parts are synchronized at a definite switching-on angle, with a transient process being observed. If the synchronization is successful the transient process oscillations are convergent, if otherwise they are divergent.

The model of synchronous machine [SM] is described by the following equations':

$$
\begin{aligned}
& i_{d}=\frac{1}{x_{d}{ }^{\prime \prime}} \cdot\left[\frac{\omega_{U}}{\omega_{\text {nom }}} \cdot E^{\prime \prime}{ }_{q}-U_{q}\right] ; \\
& i_{q}=\frac{1}{x_{d}{ }^{\prime \prime}} \cdot\left[\frac{\omega_{U}}{\omega_{\text {nom }}} \cdot E^{\prime \prime}{ }_{d}-U_{d}\right],
\end{aligned}
$$

where $i_{d}, i_{q} \quad$ are the $d q$ components of current, $\mathrm{kA}$;

$U_{q}, U_{d}$ are the $d q$ components of voltage, $\mathrm{kV}$;

$\omega_{U} \quad$ is the rotational speed of voltage vector, p.u.;

$\omega_{\text {nom }}$ is the synchronous rotational speed (at the nominal frequency $\left.\omega_{\text {nom }}=1\right)$, p.u.;

$E^{\prime \prime}{ }_{q} \omega_{U} / \omega_{\text {nom }}, E^{\prime \prime}{ }_{d} \omega_{U} / \omega_{\text {nom }}$ are the sub-transient EMF components on SM axes, $\mathrm{kV}$;

$x_{d}^{\prime \prime} \quad$ is the sub-transient reactance;

$$
\begin{aligned}
& \frac{d E_{q p}^{\prime}}{d t}=\frac{1}{T^{\prime}{ }_{d 0}} \cdot\left[E_{q e}-i_{d} \cdot\left(x_{d}-x_{d p}^{\prime}\right)-E_{q p}^{\prime}\right] ; \\
& \frac{d E^{\prime \prime}{ }_{q}}{d t}=\frac{1}{T^{\prime \prime}{ }_{d 0}} \cdot\left[E_{q p}^{\prime}-i_{d} \cdot\left(x_{d p}^{\prime}-x_{d}{ }^{\prime \prime}\right)-E_{q}^{\prime \prime}\right]+\frac{d E_{q p}^{\prime}}{d t} ;
\end{aligned}
$$

1 employing "Comparisons of synchronous machine models in the study of the transient behaviour of electrical power systems.", T.J. Hammons, D.J. Winning. Proc.IEE, vol.118, №10, October, 1971, the SM equations are written in the EMF form ( $d$ - $q$ axes). 


$$
\begin{aligned}
& \frac{d E_{d}^{\prime \prime}}{d t}=\frac{1}{T^{\prime \prime}{ }_{q 0}} \cdot\left[i_{q} \cdot\left(x_{q}-x_{d}{ }^{\prime \prime}\right)-E^{\prime \prime}{ }_{d}\right] ; \\
& x_{d p}^{\prime}=\frac{x_{d} \cdot\left(T_{d}^{\prime}-T_{d 0}^{\prime \prime}+T^{\prime \prime}{ }_{d}\right)-x_{d}{ }_{d} \cdot T^{\prime \prime}{ }_{d 0}}{T^{\prime}{ }_{d 0}-T^{\prime \prime}{ }_{d 0}}, \\
& T_{d}^{\prime}{ }_{d}=T^{\prime}{ }_{d 0} \frac{x_{d}^{\prime}}{x_{d}}, \quad T^{\prime \prime}{ }_{d}=T^{\prime \prime}{ }_{d 0} \frac{x^{\prime \prime}{ }_{d}}{x_{d}^{\prime}} .
\end{aligned}
$$

where $E_{q e}$ is the EMF of the excitation winding (proportional to the voltage), $\mathrm{kV}$; the electro-magnetic time constants $T_{d 0}^{\prime}, T_{d 0}^{\prime \prime}$ and $T_{q 0}^{\prime \prime}$ are given in seconds; the damping factor is $D=0$ in the model with $E^{\prime}=$ const; the $\omega_{U}$ value in all cases is calculated by the equation:

$$
\frac{d \omega_{U}}{d t}=\frac{1}{T_{F}} \cdot\left[\frac{d \delta_{U}}{d t} \frac{1}{\omega_{\text {nom }}}-\omega_{U}\right],
$$

where $\delta_{U}$ is the voltage vector's angle with respect to the synchronous rotation axis, rad;

$T_{f}$ is a formal constant, $\mathrm{s}$.

Other parameters of the SM model are found as

$$
\begin{aligned}
& M_{e}=E_{q}^{\prime \prime} \cdot i_{q}+E_{d}^{\prime \prime} \cdot i_{d} ; \\
& P_{G}=\frac{\omega_{U}}{\omega_{n o m}} \cdot M_{e} \\
& \frac{d s}{d t}=\frac{1}{M_{j}}\left[\frac{P_{T}}{1+s}-M_{e}\right] \\
& \frac{d \delta}{d t}=s \cdot \omega_{\text {nom }}
\end{aligned}
$$

where $M_{e}$ is the SM electro-magnetic torque, MW;

$P_{T}$ is the turbine power, MW;

$P_{G}$ is the SM electro-magnetic power, MW;

$s \quad$ is the SM rotor's slip with respect to the synchronous rotation axis, p.u.;

$\delta \quad$ is the SM rotor's angle (that is, the angle between vector $E_{g}$ and the synchronous rotation axis, rad;

$M_{j}$ is the $\mathrm{SM}$ inertia with respect to the turbine (equal to $T_{j . s} \cdot P_{G . n o m}$ ), $\mathrm{MW} \cdot \mathrm{s}$;

$D$ is the damping factor, p.u.;

$s_{U}$ is the slip of voltage vector $U$.

For each PS part, in compliance with the frequency indicated, the angular velocity reference system for all EMF and voltage vectors is applied. For this, the 
vectors of the initial slips of synchronous machine rotors and of the voltages are introduced in reference to the synchronously rotating axes:

$$
s_{r}=s_{u}\left(\frac{f}{f_{0}}-1\right),
$$

where $s_{r}$ is the rotor slip of the synchronous machine;

$s_{u}$ is the voltage vector slip; $f$ is the set frequency, $\mathrm{Hz}$;

$f_{0}$ is the rated frequency $(50 \mathrm{~Hz})$.

The rotor slips of asynchronous motors change correspondingly to the slips of voltage vectors:

$$
s_{r}(f)=s_{r}\left(f_{0}\right)-s_{u},
$$

where $s_{r}\left(f_{0}\right)$ is the rotor slip of asynchronous motor at $50 \mathrm{~Hz}$;

$s_{r}(f)$ is the rotor slip at the set frequency.

Into the set of equations describing the motion of synchronous machines, the operation of turbine turning \& excitation regulators and the asynchronous motors as well as the static part of load, the own parameter of slip compensation is introduced:

$$
\Delta s=1-\frac{f}{f_{0}},
$$

so that in all equations to the $s_{u}$ and $s_{r}$ values an extra slip $\Delta s$ is added. For example, the longitudinal- and transversal-axis equations will read as

$$
\begin{aligned}
& i_{d}=\frac{1}{x^{\prime \prime}}\left(\left(1+s_{u}+\Delta s\right) E_{q}^{\prime \prime}-U_{q}\right), \\
& i_{q}=\frac{1}{x^{\prime \prime}}\left(-\left(1+s_{u}+\Delta s\right) E_{d}^{\prime \prime}-U_{d}\right) .
\end{aligned}
$$

The following equation remains unchanged:

$$
\frac{d \delta}{d t}=s_{r} 2 \pi f_{0}=s_{r} \omega_{0} .
$$

The developed calculation program allows for independent choice of the initial frequency differences, initial voltage angles, different switching-on angles and times, PS accelerations, multi-machine schemes, etc., thus making it possible to obtain a complete picture of the influence exerted by different regime parameters on the successfulness of synchronization.

The mentioned program could successfully be used for more complicated systems. The program-aided results are presented in Fig. 11 [4].

Figure 11 displays the boundary trajectories of allowable synchronization parameters at synchronizing a $10 \mathrm{GW}$ system via a $400 \mathrm{~km}$ long $500 \mathrm{kV}$ line at various accelerations $(0.3 \mathrm{~Hz} / \mathrm{s}, 0.5 \mathrm{~Hz} / \mathrm{s}$, and $0.8 \mathrm{~Hz} / \mathrm{s})$. The trajectories are calculated taking into account that close to the synchronization place a weak variously loaded link $\left(0.56 \mathrm{P}_{\mathrm{m}}, 0.78 \mathrm{P}_{\mathrm{m}}\right.$, and $\left.0.95 \mathrm{P}_{\mathrm{m}}\right)$ is connected. In this figure it is seen that at large power flows the zone of allowable parameters noticeably narrows. 


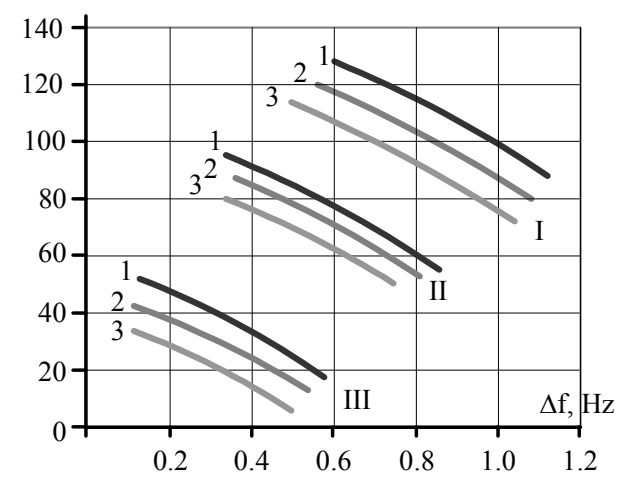

Fig. 11. Boundary trajectories for synchronization of a $10 \mathrm{GW}$ system via $400 \mathrm{~km}$ long $500 \mathrm{kV}$ lines;

$1,2,3$ - at accelerations $0.3,0.5,0.8 \mathrm{~Hz} / \mathrm{s}$, respectively; $I, I I, I I I$ - the lines added to the zone of oscillation centre with power flows $0.56 \mathrm{P}_{\mathrm{m}}, 0.78 \mathrm{P}_{\mathrm{m}}, 0.95 \mathrm{P}_{\mathrm{m}}$, respectively.

In turn, Fig. 12 shows that, depending on the power of the PS part to be synchronized, the allowable angle decreases. With the use of synchronism-check devices, synchronization will proceed at the angles not exceeding $40 \mathrm{o}$ and small acceleration and frequency differences - that is, under reliable conditions.

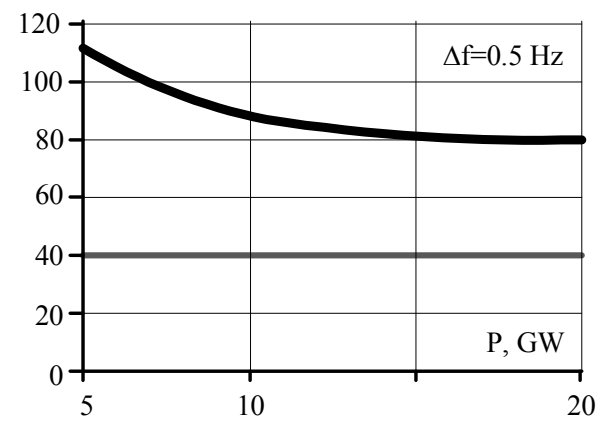

Fig. 12. The maximum allowable angle vs. the power of synchronized PS part; synchronization via a $400 \mathrm{~km}$ long $500 \mathrm{kV}$ line at accelerations $0.3 \mathrm{~Hz} / \mathrm{s}$ and frequency difference $0.5 \mathrm{~Hz}$ (the line added to the oscillation centre zone with the power flow $0.78 \mathrm{P}_{\mathrm{m}}$ ).

\section{CONCLUSIONS}

A short-term separation of the deficient region followed by self-restoration of the PS integrity using automatic synchronization can prevent the line overload as the cause of blackouts in power systems. The effectiveness of automatic synchronization has been proved by long-term experience.

Taking into account the uncertainty of a place for synchronization, for this aim in the rare emergency cases the line devices for synchronism control can be used. Switching-on in such cases is carried out mainly in the zone of negative angles.

A synchronization process can be estimated using a mathematical model aided by specially developed software.

Synchronization should proceed under the condition that the maximum angle during the transient process does not exceed the level at which an undesirable voltage drop in the network may occur. 
This process will be successful if it is stationary, with insignificant accelerations, and if the range of frequency differences is small enough.

\section{REFERENCES}

1. Barkans, J., \& Zalostiba, D. (2006). New principles of power system protection against collapse in the present stage of development. Latv. J. Phys. Tech. Sci., (3), 3-22.

2. Barkans, J., \& Zalostiba, D. (2007). Short-term splitting of a power system with its self-restoration as blackout prevention. In: IEEE Conference IPEC 2007 Proceedings, Singapore, pp.525-530.

3. Barkan, J., Markushevych, N., Rudzitis, R., \& Golubev, V. (1966). Frequency-Activated Load Shedding as an Automatic Anti-Emergency Means. Elektrycheskye Stancii (Electric Power Stations), vol.5 (in Russian).

4. Barkan, J., \& Ivanov, V. (1985). Post-Emergency Automatic Synchronization of Power System Parts. Riga: LatNIINTI (in Russian).

5. Venikov, V. (1970). Transient Electro-Mechanical Processes in Power Systems. Moscow: Visshaya shkola (in Russian).

6. Hachaturov, A. (1977). Non-Synhroniuos Reclosure and Resynhronization in Power Systems. Moscow: Energia (in Russian).

7. Barkan, J., \& Ivanov, V. (1988). Boundary trajectories for successful power grid synchronization in post-emergency regime. In: Proceedings of $1 X$ All-Union conference on power system modeling. News of Latvian SSR Academy of Science, 5, pp.107-108 (in Russian).

\section{AUTOMĀTISKĀ SINHRONIZĀCIJA KĀ ENERGOSISTĒMAS PRETSABRUKUMA KOMPLEKSA ELEMENTS}

\section{J. Barkāns, D. Žalostība}

Kops avilkums

Darbā piedāvāts jauns universāls energosistēmas pretsabrukumu komplekss, kas apvieno sevī preventīvo optimālo īslaicīgo sekcionēšanu un sistēmas normālā darba pašatjaunošanos, kas notiek automātiski bez personāla iejaukšanās. Pašatjaunošanās galvenais elements ir automātiskā sinhronizācija. Darbā parādīta iespēja šim nolūkam izmantot automātisko atpakaļ ieslēgšanu ar sinhronisma kontroles iekārtu. Aprēķina rezultāti, izmantojot vienkāršotās formulas un matemātisko modeli, parāda šīs pieejas pielietošanas lauku. Šis komplekss tika radīts, balstoties uz daudzgadīgo pieredzi avārijas procesu likvidācijā, iekārtu iespējām un sabrukuma avāriju jaunām attīstības tendencēm.

01.11 .2008 